\title{
AN INSIGHT INTO THE MASTICATORY PERFORMANCE OF COMPLETE DENTURE WEARER
}

S.F. Ahmad. An Insight into the Masticatory Performance of Complete Denture Wearer. Annal Dent Univ Malaya 2006; 13: 24-33.

To date there is no standard protocol on evaluation of the masticatory performance in complete denture wearer even though many methods had been described in the literature for measurement of the masticatory performance of the complete denture wearers. The masticatory performances were measured either subjectively or objectively, but no positive correlation was found between subjective and objective measurement. Therefore, there is a need to standardize the objective measurement, as subjective measurements rely on patients' perceptions, which is not reliable. Intra individual and inter individual variations that exist support the need to standardize the method of measurement.

Key words: masticatory performance, complete denture.

\section{INTRODUCTION}

The efficiency and success of complete dentures are difficult to measure objectively. It is important to be able to do so because patients sometimes complain with no clinical evidence $(1,2)$. Most patients expect dentures to be comparable, both functionally and esthetically, to a natural dentition (3). To predict individual patients' ability to chew test foods, dentists cannot rely on subjective responses to questionnaires on chewing difficulties or on the complete denture. However, a series of chewing tests can determine the individual masticatory performance. An objective test of masticatory performance could provide useful information of edentulous subjects wearing complete denture; later this information could support advice and decisions made by the dentists to patients on the treatment and the treatment outcome (4).

\section{OBJECTIVES}

Tooth loss is significant in elderly people, partly due to poor oral health. Fiske and Lewis (1995) suggested that oral health is important in the elderly in terms of their ability to eat healthy nutritious food (5), as elderly with a reduced number of teeth had a poor quality diet (6). It is important to have good oral health and chewing ability, either by means of the remaining teeth or with dentures (7).
Review Article

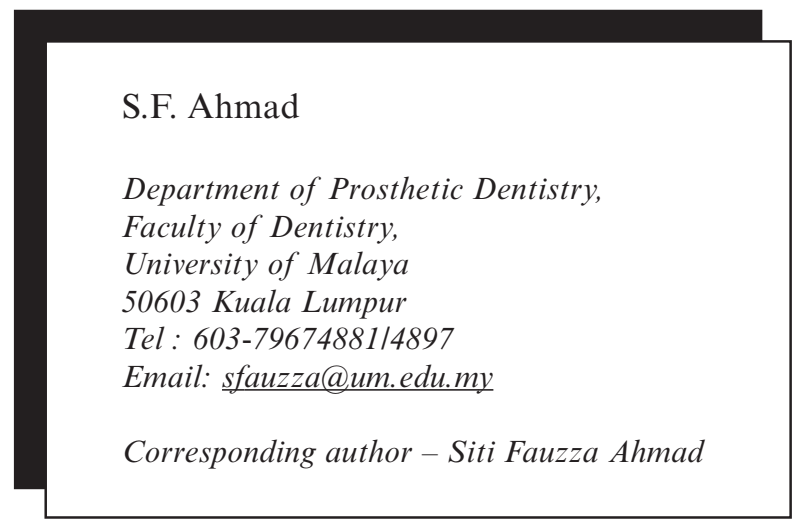

The selection of food by the elderly was affected by the number of teeth, the number of occluding pairs and the presence of complete dentures $(8,9)$. The wearing of complete dentures also resulted in changes in masticatory function compared with dentate subjects (10-12). Therefore, a measurement of the performance and the efficiency of masticatory function is important as restoring the masticatory function is one of the purposes of complete denture construction (13).

The objective of this paper is to give a brief insight into the masticatory performance and efficiency of complete denture wearers and various methods used to establish the masticatory performance of the edentulous patients.

\section{MASTICATORY FUNCTION}

\section{Definition}

"The ability of a patient to masticate is measured in two ways, i.e (1) Masticatory efficiency and (2) Masticatory performance"- Bates, Stafford and Harrison (10). From the Glossary of Prosthodontics (14), masticatory efficiency is defined as the effort required achieving a standard degree of comminution while masticatory performance is defined as a measure of the comminution of food attainable under standardized testing conditions.

\section{The process of mastication}

Mastication is the process of chewing food for swallowing and digestion (14). Mastication has been described as consisting of two separated processes, the food being placed between the teeth for it to be broken (selection) and then breakdown of the particles (breakage) once it was selected (15). In dentate subjects, grinding was random in nature but as mastication proceeds, the processes gradually become selective, with larger particles being reduced in size more rapidly than finer particles $(16,17)$. 
In complete denture wearers, mastication was a 'non-preferential' process because all particles were ground at random, contrary to natural dentitions. The difference might be because the tongue and cheeks have the extra function of retaining the dentures apart from transporting the food $(10,18)$. When the dentures moved, the tongue is used to stabilise and help to retain the dentures. This reduced the function of tongue, so as to aid in chewing by means of positioning the food bolus on the occlusal table (15). With good complete dentures, the complete denture wearers could chew almost the same pattern as a person with a natural dentition (10), but the chewing pattern will alter if the dentures loose efficiency $(15,19)$.

\section{Determining and influencing factors of the masticatory function}

Mastication was influenced by many variables for example; dental status, age, gender, denture quality, test food selection, rate of chewing and bite force.

\section{Dental state}

Subjects fitted with upper and lower complete dentures had less than one-sixth the capacity to break down food particles compared to subjects with natural teeth (20). A clear association was found between chewing efficiency and dental state $(11,21)$. It was found that the denture wearers needed significantly more chewing strokes and longer chewing times before swallowing a food bolus but no significant difference in the number of swallows found between edentulous and dentate individuals (22). Even though the average number of chews was found to remained constant with varying numbers of teeth (23), but, it was also suggested that persons with dentures do not take longer time to consume food than fully dentate persons; this might be compensated by swallowing larger particles or by avoiding hard food (17).

\section{Gender}

Studies have shown that for dentate subjects men produce finer particles and a wider particle distribution compared to women (24). Bite forces, the total contact and surface areas have also been found to be higher in dentate men than women $(7,25)$. However, no gender differences in bite force and masticatory performance was found among complete denture wearers (25).

\section{Rate of chewing}

The rate of chewing and masticatory efficiency were found to have no significant correlation (11) but wider particle size distributions were found in subjects who broke down food rapidly compared to those who broke down food slowly, regardless of dental status (15). The chewing rate of individuals with dentures nevertheless is affected by the retention and stability of their dentures and wide variation was found among them (23). With extremely good dentures, men chewed approximately 67 times before swallowing, and women chewed about 56 times. With bad prostheses, men chewed up to 94 times before swallowing and women chewed for about 78 times. However, denture wearers needed approximately seven times more chewing strokes to produce an equivalent reduction in particle size compared with young adults (26).

\section{Bite force}

Decreased masticatory efficiency was found with light chewing strokes compared to heavier strokes, which resulted in increased efficiency $(16,27)$. Maximum bite force ranging between 1 and $352 \mathrm{~kg}$ had been recorded which varies with different type of food. Studies also shown that more chewing was done at lower bite force and only a short period of time was done with high bite force (10).

Bite force gradually decreased from fully dentate subjects, subjects with fixed partial dentures, subjects with removable partial dentures and complete denture wearers (28). A study of masticatory performance in 80 year old individuals revealed that, with 20 or more teeth, the maximum bite force (MBF) was $555.5 \mathrm{~N}$, between 10 to 19 remaining teeth, MBF was $383.1 \mathrm{~N}$, from $1-9$ teeth, the MBF was $180.4 \mathrm{~N}$ and when edentulous, the MBF was $155.8 \mathrm{~N}(7)$.

The maximum bite forces also decreased when replacement dentures were first fitted (29). Therefore, for elderly patients and complete denture wearers, low bite forces are expected and for patient with severe bone resorption, initial deterioration and delayed improvement of MBF should be expected after denture replacement.

\section{Age}

Significant differences in age existed between denture wearers and dentate subjects (26). Aging caused changes to the stomatognathic system and the masticatory performance of subjects in their $70 \mathrm{~s}$ was found to be lower than the complete denture wearers of age $50(30)$.

\section{Oral sensitivity}

A positive correlation between size perception and particle size after 15 chewing strokes was found (31). Poor chewers overestimated particle size and they were more cautious of food sizes, therefore, it was suggested that poor chewers tend to swallow larger particles (31).

Tooth loss and denture replacement did not diminish the perception of shape differences as there was no relationship between oral stereognostic ability and masticatory performance in dentate subjects, or in denture wearers, with and without dentures $(32,33)$. 


\section{Intra-individual and inter-individual variation}

Intra-individual and inter-individual variations in masticatory performance were found to be very wide $(17,22,23,34)$. This might have been caused by psychological and physical variables such as stress or tiredness (35). It could also be due to the subjects being used to the chewing test; as the chewing tests progressed, the chewing performance improved (11) therefore the results of the first and the last trials showed a significant difference, although individuals had a relatively consistent rate of chewing (23).

The intra-individual variations could also relate to the test food bolus size and the chewing rate, where a small bolus size gave a wider distribution than larger portions (36). Slower chewing rate of 40 cycles/min was found to be more efficient than habitual chewing rate of 79 cycles/min in the mastication of artificial foods (23).

\section{Evaluation of mastication}

Masticatory performance has been evaluated by objective measures (masticatory tests) and subjective measures (individual perception). The individual perception of masticatory performance is often measured by questionnaire $(4,37)$. No positive correlation was found between the patients' perceptions of the ability to chew the test food with the masticatory test $(34,38,39)$. Therefore the selfassessment of chewing ability is not sufficient for evaluation of masticatory performance (21) and also it lack the necessary objectivity for repeatability and validity.

\section{METHODS TO DETERMINE AND ANALYSE MASTICATORY FUNCTION}

\section{Sieving method}

\section{a. Gravimetric sieving method}

Gaudenz introduced the gravimetric method in 1901 (40). Sieves are used such that the chewed food particles were passed through various mesh sizes. The particles accumulated on each sieve are then weighed. The weights represent the distribution of particle size and are usually presented as a percentage of the total weight accumulated. This method has been used by many authors, $(11,22,41$ 43). The sieving method was said as to be unpleasant, complicated, time consuming and prone to experimental error (44), however, many studies had also been done to show the reliability of the sieve method $(16,17,22,45-48)$ and is still considered to be a viable method.

\section{b. Volumetric sieving method}

This is an alternative method described and developed by Yurkstas \& Manly (49), which measures the volume of particles that passed through each sieve, this can be done only when the size of the specific test food was known (50).

\section{Single sieve or multiple sieves}

More detailed information on the distribution of particle sizes in chewed food can be obtained when more sieves are used $(11,23,24,26,41,43,45)$. Still, a number of authors had used single sieve to determine masticatory performances, namely Manly and Braley (1950), Kapur and Soman (1964) and Demers et al (1996).

A study was done to compare single sieve and multiple sieve methods of determining masticatory performance $(47,48)$. Even though there were significant correlations between the single sieve method and the multiple sieve method, both methods were not equally good at measuring masticatory performance. To choose an appropriate single sieve size, the sieve diameter chosen must be close to the median particle size for all subjects and the masticatory performance index must be within $20 \%$ to $80 \%$ for a reliable result. The single sieve method is certainly a convenient and reliable method to be used clinically to determine the chewing level of a subject of known masticatory index group before and after prosthetic treatment, but it was recommended to use the multiple sieve method for detailed information on masticatory performance.

\section{Colorimetric determination}

This method is done by incorporating dye in the test food (hardened formalin) to determine the surface area of chewed particles (23). The total surface area will increase as the chewing progresses. The colour content of the chewed particles then was determined colorimetrically. The natural dye colour of carrot (that was released when the carrot was chewed) (51) and the coloured artificial test food $(52,53)$ were determined spectrophotometrically. The authors found the method to be reliable and practical for assessing masticatory performance clinically.

Another colorimetric determination was measurement of the concentration of the surrounding dye colour of the test food $(39,54)$. It was found that the change in concentration of the surrounding dye solution is proportionate to the area of the chewed particles. The colorimetric method, however, appeared time consuming and less accurate and less reproducible than sieving method (43). The method also did not show the distribution of the chewed particle size (19).

\section{Optical Scanning method}

The optical scanning system uses a video camera and a computer. A Seescan device was used to count and measure the size of the chewed particles $(55,56)$. The chewed particles must be vibrated evenly to prevent overlapping on a platform with a black 
background and then scanned in monochrome. Due to the ability of the optical scanning to count and size individual particles in a direct way, the detailed form of particles could be obtained for the study of food fracture behaviour (55). However, this method is time consuming when there are too many separate particles so there is a need to use sieves to reduce the number of the chewed particles prior to scanning (46).

\section{Direct photographic measurement}

A graphic digitizer and computer was used to measure particle sizes and analyze the distributions $(13,19)$. A stereomicroscope was used to photograph the chewed particles then the photos were magnified 14 times. However, the number of chewing strokes and the number and size of chewed particles measured affected the frequency distribution of the particles. The author found that too many strokes will not show the deficiency in masticatory efficiency as this will produce many numbers of particles and too few strokes will not give accurate results for frequency distributions. Therefore, the author suggested that the chewed particles are selected randomly and to measure at least 200 to 400 chewed particles with this method to prevent bias results and to get correct frequency distribution. On the other hand, the authors found this method convenient, simple and reliable for particle size frequency distribution, and avoid an error that occurs from weighing particles in sieving method.

\section{Image analysis}

An image of the masticated test food was recorded in a video camera and was then analysed with image analyser (44). The samples must be spread evenly on a petri dish to prevent overlapping or air bubbles before being recorded on video camera. Particles smaller than $0.25 \mathrm{~mm}^{2}$ were eliminated by means of "electronic sieving" to prevent the computer from including the artefacts, examples; air bubbles and debris. The authors felt that image analysis was simple, rapid, accurate and highly reproducible and can be used to measure a large number of samples.

\section{Measurement of masseter muscle volume}

It was suggested that the size of the masseter muscle is a determining factor of chewing force and function (57). But, the authors found that the muscle power exerted in the test is not closely related to the muscle size. Although harder food required longer muscle contraction time, but no changes detected in bite force to break and to chew food.

\section{Weight loss of visco elastic food}

The calculation of masticatory efficiency (ME) was done by measuring the percentage of weight loss that occurs at the end of every chewing stroke of chewing gum (58). A linear relationship was found between the rate of weight loss and number of chewing strokes. The authors concluded that for functional assessment of older people, measuring ME by means of weight loss from chewing gum could be used.

\section{Comparison between optical scanning and sieving}

A sieving method and optical scanning method was compared to determine particle size distribution (49). They found that optical scanning gave 30\% overestimation of median particle size compared to results obtained by sieving. The authors suggested that to measure chewing efficiency where median particle size by weight or volume was required, sieving is a more direct method than optical scanning as the weight of the particles is directly measured. The optical scanning method however, would be an advantage for studying the characteristic of the chewed particles, the fracture behaviour of the test food or when using coloured particles. Nevertheless, both methods gave a satisfactory measure of masticatory efficiency but skills were needed to use the optical scanning method (59).

\section{Comparison of data analyzing method of particle size distributions}

Three methods of analysing mixtures of chewed particles were compared: a cumulative volume distribution, a volume distribution and a number distribution (60). With the sieving method, the results obtained were often described as weight distributions or cumulative weight distributions. For a known mass of the test food, the results can also be described by volume or cumulative volume distributions. With optical scanning, the results were obtained as number of particles, volume distributions or cumulative volume distributions. They found that the median particle size could not be used to compare between masticatory efficiency studies. The median particle size is mainly determined by larger number of small size particle. Larger particles actually have a large influence on the chewing process but the number of larger particles was small, so had very little influence on the median. The influence of larger particles size in chewing was that food particle size was found to be a criterion for the initiation of swallowing (61) and also the maximum jaw gape during the chewing cycle appeared to be related to the height of the largest particles in the mouth (62). Therefore, cumulative weight distributions and cumulative volume distributions are preferred to describe the particle size distribution.

\section{TEST FOOD}

\section{Criteria for test food}

The masticatory performance depends on type of test food, the size and shape of the bolus, the 
number of chews and method used to quantify the performance $(24,35,63)$. In masticatory function tests, either natural test food or artificial test food may be used.

Subjects generally indicated that sticky food (example, soft breads and pancakes) and tough food substances caused trouble in chewing while soft, firm, and firm and brittle substances are comparatively easy to cope with (23).

The test food should be selected from foods that are normally consumed and offer a proper degree of difficulty so as to give normal dentition a high rating and deficient dentition a poor rating (17). The test food should give an appropriate range of difficulty so as to measure the differences in masticatory performance among denture wearers (18). Very hard and very soft foods would not be suitable as very soft food did not required chewing and very hard food needed too much effort and denture patients had difficulties in masticating tough food (16).

\section{Natural test food}

The use of natural test food was said to cause a lot of variation due to their physical properties such as fracture strength, sizes and shape (43). Natural food were frequently inhomogeneous and different food preparation might lead to diverse effects in terms of force generation and jaw movement (64).

Carrots were found to be the most suitable natural test food for complete denture wearer $(17,18,37,51,65)$. Apart from carrot, coffee beans $(40,66)$, almond $(42,46,55,56,59)$, peanuts $(67,68)$, soya beans $(13,19)$, boiled white egg, apple, bread, shredded coconut, meat, cracked corn, raisins (17), and cylindrical coconut (41) have all been used.

\section{Salted peanuts, shredded coconut, carrots and raisins}

With gravimetric sieving method, $80 \%$ of the weight of the test food could be recovered, when subjected to 20 chewing strokes, sieved, and collected on filter paper and dried (17). $20 \%$ was lost by swallowing, by solution, or by emulsification of food or loss of its moisture content. Shredded coconut needed more chewing strokes, as it is tough but raisins were found not suitable for gravimetric sieving analysis.

\section{Almond}

Bagged almond was used to eliminate problems of loss of small chewed particles and problems of small particles getting under the dentures and inhibiting chewing (55). To reduce the oil content of the almond, the whole almond could be microwaved, which results in less clumping and eliminates the need to dry or wash the particles (46).

\section{Soya bean}

The soya had to be soaked and boiled in water to eliminate the raw taste of the beans and to maximize the water content in the beans so that no more water absorption occurred when the particles were chewed $(13,19)$. Because the soya bean was softened, the bite force could not be measured as a factor affecting masticatory efficiency, apart from that, soya bean is not suitable for the sieving method as it could not passed through the sieves easily (66).

\section{Coffee beans}

Coffee beans were suggested as giving satisfactory results in mastication test (66). A large variation of hardness within samples were found, therefore they suggested that a group of eleven coffee beans should be used for a single test and only five chewing strokes need to be applied at each test. The authors considered them to be reproducible and, for accuracy, they proposed the chewing test should be repeated five times. But the authors did not try the coffee bean on complete denture wearers.

\section{Artificial test food}

Artificial test food can be more consistent in terms of size, shape and texture (45). However, artificial test food with high fracture strength in proportion to the maximum bite force of subjects with fewer teeth (or edentulous) may prevent the measurement of their masticatory performance and efficiency (69). Several criteria for ideal test food requirement were outlined by Dahlberg (1942)(23):

1. The test material should be able to be chewed even by people with poor teeth and can be reduced to small pieces.

2. The consistency should nearly correspond to real food (example, raw carrot and boiled liver)

3. The fracture strength in loading and compressibility must be known.

4. Proved to have a homogenous character.

The earliest work on silicone was by Edlund \& Lamm (1980) (45). Ever since, Optosil ${ }^{\circledR}$ was widely used $(26,50,60,68,69)$. Optocal (69), Optocal Plus $(27,31,47,48)$, CutterSil $^{\circledR}(24,35,63)$, chewing gums $(53,58,70)$, irreversible hydrocolloid impression material $(34,43)$, gelatine $(23,38,54)$, paraffin wax (72) and mixture of calcium carbonate $\left(\mathrm{CaCO}_{3}\right)(57)$ also have been used as test food.

\section{Gelatine}

Gelatine materials are hardened in formalin to avoid dissolving the material in water (23). The gelatine cubes have to be packed in plastic bags with a saturated humidity and stored in cold storage when not in use because at normal humidity the gelatine hardened by formalin is not constant $(38,54)$. After 2 minutes placed in saliva, the volume decreases by approximately $0.5 \%$ because the water evaporates when the surrounding has a higher salt content than gelatine. A few subjects found gelatine as unpleasant 
to chew and some subjects compared the bite force required as similar to chewing apple or cartilage. The production and storage of the gelatine was said to be complicated (52).

\section{Silicone}

\section{i. Optosil $^{\circledR}$}

The results of particle size distributions using Optosil ${ }^{\circledR}$ cubes (Polyvinylsiloxane - addition silicone impression material) were reproducible $(4,26,45)$. The advantages of Optosil ${ }^{\circledR}$ are definite shape and size can be produced, unaffected by saliva and the food can be coloured. But, it was found that relatively high proportion of edentulous subjects were unable to comminute Optosil ${ }^{\circledR}$ due to larger forces needed to break it than natural foods such as carrots and peanuts $(4,26)$. Therefore, they suggested that the masticatory performance tests for edentulous subjects should be improved by using an artificial test food with highly reproducible physical properties and fracture strength comparable to natural foods.

\section{ii. Cuttersil $^{\circledR}$}

Cuttersil ${ }^{\circledR}$ is a silicone impression material marketed after Optosil ${ }^{\circledR}$. The Cuttersil tablet can be kept for 7 days due to its dimensional stability (63). Error between operators was found to be high compared to the differences between batches of Cuttersil ${ }^{\circledR}$ but the authors found it to be reliable and easily reproducible for masticatory tests.

\section{iii. Optocal}

Optocal was prepared to have properties of Optosil ${ }^{\circledR}$ but with a softer consistency to overcome the difficulties of complete denture wearers with chewing Optosil ${ }^{\circledR}(69)$. Dental silicone Optosil ${ }^{\circledR}$ was mixed with toothpaste, Vaseline petroleum jelly, dental plaster and alginate powder. Even though dissolution occurred and weight loss from $4 \%$ to $18 \%$ was found, the author alleged that the effects of dissolution of the constituents of Optocal on particle size distributions were negligible. Optocal had lower resistance to deformation and failure than Optosil ${ }^{\circledR}$, it was also reproducible in form and consistency. Optocal was less stiff and less brittle than peanuts or Optosil ${ }^{\circledR}$ and carrots but stronger than peanuts, and about equal strength with carrots. Optocal is suggested as suitable as a test food for any type of dentition although no study was found (as known) to have use Optocal for complete denture wearers.

\section{Mixture of Calcium Carbonate ( $\mathrm{CaCO})_{3}$}

A mixture of $\mathrm{CaCO}_{3}$, microcrystalline cellulose and a small amount of $\mathrm{MgO}$ were used as ingredients of test food (57). These mixtures were produced in tablet form with different hardness but with similar texture and appearance. The authors found that their prefabricated test food could be used for masticatory tests.

\section{Chewing gum}

The gum was found to resemble cooked food and processed food, which became visco-elastic when few numbers of chewing strokes were applied $(58,70)$. The gums used did not stick to the dentures or get under the dentures. The used of gums eliminate the complicated measurement with sieving and direct measurement of the chewed particles (53). Both author agreed that gum can be used to measure masticatory performance clinically.

\section{Irreversible hydrocolloid (alginate)}

Alginate was used to develop a simple method in measuring masticatory performance, but the test was done on dentate subjects (43). The method described by Ohara et al (2003), was then used on complete denture wearers (34). Even though the alginate was found to be suitable for complete denture wearer, further investigations need to be done as to compare the hardness of the alginate with natural test food and other artificial test food, for example, silicone type test food (34).

\section{SUMMARY OF THE LITERATURE REVIEW}

Edentulous patients benefit from wearing complete denture in two respects, psychological and physiological. One of the main purposes of wearing complete dentures is function, especially eating. It has been reported that there is a decrease in variation of type of food intake in edentulous patients due to poor chewing ability.

Psychological, denture comfort, adaptation to dentures and tongue control are some factors influencing patients chewing ability. Apart from that, age, gender, bite forces, chewing rate and oral sensitivity also affected the masticatory function. Therefore, it is important to evaluate the effectiveness of complete dentures via the masticatory performances. This will assist the dentist to give proper advice for patients which might also include support for dietary advice.

Several methods have been used to measure the masticatory function, and the most common use is the sieving method. All the methods used however, were thought as reliable for masticatory function test. The results from the method were obtained as weight distributions or volume distribution or as number of particles.

Both natural and artificial test food have been used. Natural test food has problems of lack of consistency and reproducibility. Artificial test food can be reproduced and the size, shape and texture can be controlled. It is also can be non-allergenic. 
The most popular artificial test food use at the moment is silicone dental impression material.

Because of the variability of methods and test food used, it is difficult to determine the true masticatory index for complete denture wearers. The intra-individual and inter-individual variations that exist support the need to standardise the method and the test food. Nevertheless, nutritional assessment, counseling, and dietary advice are important to improve the diet quality of complete denture wearers $(72,73)$.

\section{CONCLUSION}

A method to determine the masticatory performance must be cheap, simple to be used and reproducible. The test food used must be able to be disinfected prior testing in the laboratory. However, a simpler method that eliminates the necessity of laboratories procedure by means of chair side testing is favourable and rapid. A computer aided device, for example; an image analyser seems to fit the requirement, provided it is used clinically. Therefore, a reliable way of measuring the masticatory performance of the complete denture wearers need to be properly established, later it will help in assessing the effectiveness of complete denture and patients' treatment need.

\section{REFERENCES}

1. Al-Quran F, Clifford T, Cooper C \& Lamey PJ. Influence of psychological factors on the acceptance of complete dentures. Gerodont 2001; 18(1): 35-40.

2. Wolff A, Gadre A, Begleiter A, Moskona D \& Cardash H. Correlation between patient satisfaction with complete dentures and denture quality, oral condition, and flow rate of submandibular/sublingual salivary glands. Int $\mathbf{J}$ Prosthodont 2003; 16(1): 45-48.

3. Davis EL, Albino JE, Tedesco LA., Portenoy BS \& Ortman LF. Expectations and satisfaction of denture patients in a university clinic. J Prosthet Dent 1986; 55(1): 59-63.

4. Slagter AP, Olthoff LW, Bosman F \& Steen WH. Masticatory ability, denture quality, and oral conditions in edentulous subjects. J Prosthet Dent 1992a; 68(2): 299-307.

5. McGrath C \& Bedi R. The importance of oral health to older people's quality of life. Gerodont 1999; 16(1): 59-63.
6. Daly RM, Elsner RJ, Allen PF \& Burke FM. Associations between self-reported dental status and diet. J Oral Rehabil 2003; 30(10): 964-70.

7. Tatematsu M, Mori T, Kawaguchi T, Takeuchi K, Hattori M, Morita I, Nakagaki H, Kato K, Murakami T, Tuboi S, Hayashizaki J, Murakami H, Yamamoto M \& Ito Y. Masticatory performance in 80-year-old individuals. Gerodont 2004; 21(2): 112-9.

8. Sheiham A, Steele JG, Marcenes W, Finch S \& Walls AW. The impact of oral health on stated ability to eat certain foods; Findings from the National Diet and Nutrition Survey of older people in Great Britain. Gerodont 1999; 16(1): 11-20.

9. Farrell JH. The effect of mastication on the digestion of food. Brit Dent J 1956; 100(6): 14955 .

10. Bates JF, Stafford GD \& Harrison A. Masticatory function - a review of the literature. III. Masticatory performance and efficiency. J Oral Rehabil 1976; 3(1): 57-67

11. Helkimo E, Carlsson GE, \& Helkimo M. Chewing efficiency and state of dentition- A methodologic study. Acta Odontol Scand 1978; 36: 33-41.

12. Carlsson GE. Clinical morbidity and sequelae of treatment with complete denture. J Prosthet Dent 1998; 79(1): 17-23.

13. Shi CS, Ouyang G \& Guo TW. Comparison of food particle distribution masticated by subjects wearing complete dentures and with natural teeth. J Oral Rehabil 1990b; 17: 611-5.

14. Glossary of Prosthodontics. J Prosthet Dent 2005; 94 (1):1-83.

15. Lucas PW, Luke DA, Voon FC, Chew CL \& Ow R. Food breakdown patterns produced by human subjects possessing artificial and natural teeth. J Oral Rehabil 1986; 13(3): 205-14.

16. Yurkstas AA. The masticatory act: a review. J Prosthet Dent 1965; 15(2): 248-60.

17. Manly RS \& Braley LC. Masticatory performance and efficiency. J Dent Res 1950; 29(4): 448-62. 
18. Kapur K, Soman S, \& Yurkstas A. Test foods for measuring masticatory performance of denture wearers. J Prosthet Dent 1964; 14(3): 483-91.

19. Shi CS, Ouyang G \& Guo TW. Masticatory efficiency determined with direct measurement of food particles masticated by subjects with natural dentitions. J Prosthet Dent 1990a; 64(6): 723-6.

20. Kapur KK \& Soman SD. Masticatory performance and efficiency in denture wearers. J Prosthet Dent 1964; 14: 687-94.

21. Miura H, Araki Y, Hirai T, Isogai E, Hirose K \& Umenai T. Evaluation of chewing activity in the elderly person. J Oral Rehabil 1998; 25: 1903.

22. Dahlberg B. The masticatory habits. J Dent Res 1946; 25: 67-72.

23. Dahlberg, B. The masticatory effect. Acta Med Scand 1942; 139 (Suppl.): Ch. 15.

24. Julien KC, Buschang PH, Throckmorton GS \& Dechow PC. Normal masticatory performance in young adults and children. Arch Oral Biol 1996; 41(1): 69-75.

25. Yamashita S, Sakai S, Hatch JP \& Rugh JD. Relationship between oral function and occlusal support in denture wearers. J Oral Rehabil 2000; 27: 881-6.

26. Slagter AP, Olthoff LW, Steen WH \& Bosman F. Comminution of food by complete-denture wearers. J Dent Res 1992b; 71(2): 380-6.

27. Fontijn-Tekamp FA, Slagter AP, Van der Bilt A, 'T Hof MA, Witter DJ, Kalk W \& Jansen JA. Biting and chewing in overdentures, full dentures, and natural dentitions. J Dent Res 2000; 79(7): 1519-24.

28. Miyaura K, Morita M, Matsuka Y, Yamashita A \& Watanabe T. Rehabilitation of biting abilities in patients with different types of prostheses. J Oral Rehabil 2000; 27: 1073-6.

29. Muller F, Heath MR \& Ott R. Maximum bite force after the replacement of complete dentures. Gerodont 2001; 18(1): 58-62.
30. Koshino H, Hirai T, Ishijima $\mathrm{T}$ \& Ikeda Y. Tongue motor skills and masticatory performance in adult dentates, elderly dentates, and complete denture wearers. J Prosthet Dent 1997; 77(2): 147-52.

31. Engelen L, Van der Bilt A \& Bosman F. Relationship between oral sensitivity and masticatory performance. J Dent Res 2004; 83(5): 388-92.

32. Garrett NR, Kapur KK \& Jochen DG. Oral stereognostic ability and masticatory performance in denture wearers. Int $\mathbf{J}$ Prosthodont 1994; 7(6): 567-73.

33. Hirano K, Hirano S \& Hayakawa I. The role of oral sensorimotor function in masticatory ability. J Oral Rehabil 2004; 31: 199-205.

34. Ahmad SF \& Lyons MF. Assessment of masticatory performance in complete denture wearers. University of Glasgow, 2004. Masters. thesis

35. Lassauzay C, Peyron MA, Albuisson E, Dransfield E \& Woda A. Variability of the masticatory process during chewing of elastic model foods. Eur J Oral Sci 2000; 108(6): 48492.

36. Buschang PH, Throckmorton GS, Travers KH \& Johnson G. The effects of bolus size and chewing rate on masticatory performance with artificial test foods. J Oral Rehabil 1997; 24(7): 522-6.

37. Demers M, Bourdages J, Brodeur JM, \& Benigeri $M$. Indicators of masticatory performance among elderly complete denture wearers. J Prosthet Dent 1996; 75(2): 188-93.

38. Garrett NR, Perez P, Elbert C \& Kapur KK. Effects of improvements of poorly fitting dentures and new dentures on masticatory performance. J Prosthet Dent 1996; 75(3): 26975 .

39. Gunne HS, Bergman B, Enbom L \& Hogstrom J. Masticatory efficiency of complete denture patients. A clinical examination of potential changes at the transition from old to new denture. Acta Odontol Scand 1982; 40(5): 28997. 
40. Schneider G \& Senger B. Clinical relevance of a simple fragmentation model to evaluate human masticatory performance. J Oral Rehabil 2002; 29(8): 731-6.

41. Christiansen EG. The chewing power of teeth. Brit Dent J 1924; 45: 318.

42. Ow RK, Carlsson GE \& Karlsson S. Relationship of masticatory mandibular movements to masticatory performance of dentate adults: a method study. J Oral Rehabil 1998; 25(11): 821-9.

43. Ohara A, Tsukiyama Y, Ogawa T \& Koyano K. A simplified sieve method for determining masticatory performance using hydrocolloid material. J Oral Rehabil 2003; 30(9): 927-35.

44. Mahmood WA, Watson CJ, Ogden AR \& Hawkins RV. Use of image analysis in determining masticatory efficiency in patients presenting for immediate dentures. Int $\mathbf{J}$ Prosthodont 1992; 5(4): 359-66.

45. Edlund J \& Lamm CJ. Masticatory efficiency. J Oral Rehabil 1980; 7(2): 123-30.

46. Al-Ali F, Heath MR \& Wright PS. Simplified method of estimating masticatory performance. J Oral Rehabil 1999; 26: 678-83.

47. Van der Bilt A \& Fontijn-Tekamp FA. Comparison of single and multiple sieve methods for the determination of masticatory performance. Arch Oral Biol 2004a; 49(2): 15560.

48. Van der Bilt A \& Fontijn-Tekamp FA. Comparison of single and multiple sieve methods for the determination of masticatory performance. Arch Oral Biol 2004b; 49(3): 1938.

49. Yurkstas A \& Manly RS. Masticatory ability and tests food. J Appl Physiol 1950; 3: 45-53.

50. Van der Bilt A, van der Glas HW, Mowlana F \& Heath MR. A comparison between sieving and optical scanning for the determination of particle size distributions obtained by mastication in man. Arch Oral Biol 1993b; 38(2): 159-62.

51. Kayser AF \& van der Hoeven JS. Colorimetric determination of the masticatory performance. J Oral Rehabil 1977; 4(2): 145-8.
52. Huggare J \& Skindhöj B. A new method for assessing masticatory performance: a feasibility and reproducibility study. J Oral Rehabil 1997; 24: 490-5.

53. Hayakawa I, Watanabe I, Hirano S, Nagao M \& Seki T. A simple method for evaluating masticatory performance using a colorchangeable chewing gum. Int $\mathrm{J}$ Prosthodont 1998;11(2): 173-6.

54. Gunne HS. Masticatory efficiency. A new method for determination of the breakdown of masticated test material. Acta Odontol Scand 1983; 41(5): 271-6.

55. Mowlana F \& Heath R. Assessment of masticatory efficiency: new methods appropriate for clinical research in dental practice. Eur J Prosthodont Restor Dent 1993; 1(3): 121-5.

56. Mowlana F, Heath MR \& Auger D. Automated optical scanning for rapid sizing of chewed food particles in masticatory tests. J Oral Rehabil 1995; 22(2): 153-8.

57. Shiau YY, Peng CC \& Hsu CW. Evaluation of biting performance with standardized test-foods. J Oral Rehabil 1999; 26(5): 447-52.

58. Anastassiadou V \& Heath MR. The development of a simple objective test of mastication suitable for older people, using chewing gums. Gerodont 2001; 18(2): 79-86.

59. Mowlana F, Heath MR, Van der Bilt A \& van der Glas HW. Assessment of chewing efficiency: a comparison of particle size distribution determined using optical scanning and sieving of almonds. J Oral Rehabil 1994; 21(5): 545-51.

60. Van der Bilt A, Abbink JH, Mowlana F \& Heath MR. A comparison between data analysis methods concerning particle size distributions obtained by mastication in man. Arch Oral Biol 1993a; 38(2): 163-7.

61. Lucas PW \& Luke DA. Is food particle size a criterion for the initiation of swallowing? J Oral Rehabil 1986; 13(2): 127-36.

62. Van der Bilt A, van der Glas HW, Olthoff LW \& Bosman F. The effect of particle size reduction on the jaw gape in human mastication. J Dent Res 1991; 70(5): 931-7. 
63. Albert TE, Buschang PH \& Throckmorton GS. Masticatory performance: a protocol for standardized production of an artificial test food. J Oral Rehabil 2003; 30(7): 720-2.

64. Wang JS \& Stohler CS. Textural properties of food used in studies of masication. J Dent Res 1990; 69(9): 1546-50.

65. Garrett NR, Kaurich M, Perez P \& Kapur KK. Masseter muscle activity in denture wearers with superior and poor masticatory performance. J Prosthet Dent 1995; 74(6): 628-36.

66. Schneider G \& Senger B. Coffee beans as a natural test food for the evaluation of the masticatory efficiency. J Oral Rehabil 2001; 28: 342-8.

67. Hirai T, Ishijima T, Koshino H \& Anzai T. Agerelated change of masticatory function in complete denture wearers: evaluation by a sieving method with peanuts and a food intake questionnaire method. Int J Prosthodont 1994; 7(5): 454-60.

68. Olthoff LW, Van der Bilt A, Bosman F \& Kleizen HH. Distribution of particle sizes in food comminuted by human mastication. Arch Oral Biol 1984; 29(11): 899-903.
69. Slagter AP, van der Glas HW, Bosman F \& Olthoff L. W. Force-deformation properties of artificial and natural foods for testing chewing efficiency. J Prosthet Dent 1992c; 68(5): 790-9.

70. Heath, M R. The effect of maximum biting force and bone loss upon masticatory function and dietary selection of the elderly. Int Dent J 1982 Dec; 32(4): 345-56.

71. Sato H, Fueki K, Sueda S, Sato S, Shiozaki T, Kato M \& Ohyama T. A new and simple method for evaluating masticatory function using newly developed artificial test food. J Oral Rehabil 2003; 30(1): 68-73.

72. Allen F \& McMillan A. Food selection and perceptions of chewing ability following provision of implant and conventional prostheses in complete denture wearers. Clin Oral Implants Res 2002; 13(3): 320-6.

73. Shinkai RS, Hatch JP, Rugh JD, Sakai S, Mobley CC \& Saunders MJ. Dietary intake in edentulous subjects with good and poor quality complete dentures, J Prosthet Dent 2002; 87(5): 490-8. 